\title{
Digital Publishing: tension and attention
}

\author{
Paul Squires \\ Perini \\ 3 The Gallery, Marston Street, Oxford OX4 1LF \\ paul.squires@perininetworks.com
}

\section{INTRODUCTION}

The ways in which we both produce and consume content has been a constant state of technologyled evolution. However, the perceived speed of change is now greater, and with that speed comes disruption (as was the case with the music industry around a decade ago). This work will look at the "content economy" - where it has come from, where it is going, and whether the world of iPad-clutching consumers sipping on a Starbucks while browsing micro-paid content is the reality that we are moving to - and whether it is something that we innately desire.

\section{IF "CONTENT IS KING", IS DIGITAL PUBLISHING THE NEW MONARCHY?}

The definition of "digital publishing" is, itself, undergoing a fundamental reframing. Formerly associated with disciplines such as DTP, it now encompasses a broader range of consumer-driven production and consumption activities.

\subsection{What are the new online currencies?}

The explosion in the availability of content, and the ability to produce it, fuelled by a powerful concoction of mass communications and highquality consumer devices, has challenged definitions of value.

The grounding that the Internet (and the web) has in free-at-the-point-of-use culture has led to a default position of free-in-the-market content, often funded by a mix of display advertising and business services.

Where there is an abundance of free content (in every sense), it brings into question what the new currencies actually are. How are choices made in online content? One such currency is attention. Another is interest (or, rather, the ability to be interesting). How subjective is this? How can mass audiences be developed when our ideas of attention and currency vary widely?

\subsection{How different is differentiation?}

There are many free services, which allow anyone to contribute and publish original content to millions. However, the ability to do it doesn't make it interesting, or worthy, by default - but the potential is extraordinary.

\subsection{What is the effect on other media and production ecosystems?}

There is a view from a certain tranche of media commentators and academics, that print is dead. The reality is that nothing truly dies, but simply finds its place - after a considerable and fundamental disruption and re-analysis - as part of a different ecosystem. When a re-evaluation of printed content takes place, it occupies a very different position. The answer of whether print will die will be tackled in the presentation itself!

\section{REFERENCES}

Imperica. www.imperica.com, Perini, 2010-2011. 